Article

\title{
Spatial Statistical Assessment of Groundwater PCE (Tetrachloroethylene) Diffuse Contamination in Urban Areas
}

\author{
Licia C. Pollicino ${ }^{1,2}{ }^{2}$, Marco Masetti ${ }^{1}$, Stefania Stevenazzi ${ }^{1, *}$, Loris Colombo ${ }^{2} \mathbb{D}$ and \\ Luca Alberti 2 (D) \\ 1 Dipartimento di Scienze della Terra “A. Desio”, Università degli Studi di Milano, 20133 Milan, Italy; \\ licia.pollicino@unimi.it or liciacamilla.pollicino@polimi.it (L.C.P.); marco.masetti@unimi.it (M.M.) \\ 2 Dipartimento di Ingegneria Civile e Ambientale (DICA), Politecnico di Milano, 20133 Milan, Italy; \\ loris.colombo@polimi.it (L.C.); luca.alberti@polimi.it (L.A.) \\ * Correspondence: stefania.stevenazzi@unimi.it
}

Received: 2 April 2019; Accepted: 3 June 2019; Published: 10 June 2019

\begin{abstract}
Contamination by chlorinated solvents is typically associated with point sources, which are able to release high concentrations and to generate well defined plumes. Nevertheless, in urban settings (especially in functional urban areas-FUAs), multiple-point sources are frequently present, consisting of a series of unidentifiable small sources clustered within large areas, generating a diffuse, anthropogenic contamination. This situation results in the coexistence of single plumes with higher contaminant concentrations, and larger areas where the concentration is lower but still higher than the maximum admissible concentration limits. This paper proposes a methodology devised to cope with the diffuse contamination by chlorinated solvents within shallow aquifers due to multiple-point sources in FUAs. The approach is based on a Bayesian model that helps to spatially evaluate the likelihood of having active multiple-point sources, and to relate their impact on the shallow aquifer to the hydrogeological features of the area. Moreover, the approach allows testing of the efficiency of the monitoring network to properly characterize the contamination in the aquifer. The consistency of the results of the analysis was also checked for the Milan FUA (Italy) by a comparison to a previous study, performed through an inverse numerical modelling approach within a Monte Carlo statistical framework to identify the areas with the highest likelihood to host potential multiple-point sources.
\end{abstract}

Keywords: chlorinated solvents; diffuse contamination; urban groundwater; Bayesian model; Milan

\section{Introduction}

In 2006, the European Union (Groundwater Directive, 2006/118/EC, [1]) set water quality objectives that should be achieved by 2015 in each groundwater body within each member country. The aim of the European Union (EU) was to regulate procedures at the scale of groundwater bodies, leaving the responsibility for local point source contaminations at the national level. However, it was already clear in 2009 [2] that each member state had local critical situations, mainly concerning shallow, unconfined aquifers that could hamper the achievement of the objectives due to the existence of diffuse contaminated areas. The development of functional urban areas (FUAs) has an ever-growing relationship with the presence of wide areas with contaminated groundwater, where it is difficult to identify the locations of the contamination sources. This has been a common environmental issue in many developed countries for many years [3], contributing to the failure to reach water quality objectives in many aquifers within Europe [4]. This failure has a huge economic impact on society due to the management and remediation costs that these situations require, and the associated soil use conflicts in urban area redevelopment. The causes of contamination in FUAs can be roughly 
classified into three different classes: (a) point sources (PS), contamination hot spots corresponding to areas releasing plumes of high concentrations; (b) non-point sources (NPS), where the contaminant load comes from the development of anthropogenic activities over large areas (e.g., built up areas, extended suburbs); and (c) multiple-point sources (MPS), where the contaminant load comes from a series of point sources that release a low contaminant mass, are clustered within a relatively large area (e.g., industrial district), and consequently are difficult to localize individually. The present paper focuses on MPS, and on identification not of each single one, but of the areas that most probably contain them.

In FUAs, a multitude of contamination PS requires effective intervention at a medium scale that is neglected in existing legislation. Dealing with groundwater contamination at the urban scale falls in the gap between EU regulations (NPS) and national legislation (local PS). Frequently, the problem with FUAs is that many districts prone to diffuse contamination (caused by MPS) cannot be managed with the usual remediation techniques used for small contaminated sites, for three main reasons: (a) the difficulty in identifying specific point sources due to the low mass released, (b) the wide extent of the contaminated areas, and (c) the complexity of designing appropriate networks for monitoring contamination extent. These aspects require alternative approaches that are consistent with groundwater policy horizons [5]. The above-mentioned conditions are mainly related to the historical urban and industrial development of the areas, where the potential sources of contamination that can affect groundwater quality have been subjected to many changes. The picture becomes even more complex when considering that, in both cases, the contamination can also be related to past land use conditions that are not completely known in terms of location, type, and duration. Furthermore, the increase of urban areas may threaten the quality of groundwater because of the strong influence brought by changes in land use [6]. The extension of sewage system networks and the inadequacy of old sewer systems for augmented effluent loads are known worldwide as important MPS of contamination in urban areas $[7,8]$. To cope with this environmental and economic problem, there is a need to develop scientifically based approaches to help address the most appropriate solutions to better support the identification of urban areas where potential multiple-point sources could be present.

As one of the most relevant urbanized and industrialized zones in Europe, the Lombardy region presents many of the features that recently inspired the development of specific legislative actions to try to cope with the problem [9]. This fact, together with the considerable amount of research that has been carried out, data availability, and the presence of good groundwater monitoring networks, offers the possibility to find excellent pilot areas within the region that can be analyzed to propose new solutions for the prevention and management of diffuse contaminated areas.

In this study, we develop a new approach to cope with diffuse contamination by chlorinated solvents within shallow aquifers due to multiple-point sources in FUAs. The approach is based on a Bayesian model that helps us to spatially evaluate the likelihood of having active MPS, and to relate their impact on shallow aquifers to the hydrogeological features of the area. Moreover, the approach allows testing of the efficiency of the monitoring network to properly characterize the contamination in the aquifer as an essential element from a groundwater management perspective, as well as in terms of groundwater risk assessment [10]. The consistency of the results of the analysis was checked by comparison to a previous study performed through an inverse numerical modelling approach within a Monte Carlo statistical framework [11].

\section{Study Area}

The study area is located in the Lombardy region, within the Po Plain in Northern Italy, and it includes the north-eastern sector of Milan city and some surrounding municipalities (Figure 1). The area is about $240 \mathrm{~km}^{2}$, and in the past it was characterized by a dense agglomeration of both residential buildings and industrial activities, such as automotive, refineries, chemical plants, stills, and tire production, which have been historically located in this area since the 1960s [12]. This territory is characterized by a natural hydrographic network as well as a man-made one. The first is made up of 
the Seveso River on the west side and the Lambro River on the east. The latter includes the Naviglio Martesana on the south-east side and the Villoresi Canal on the north.
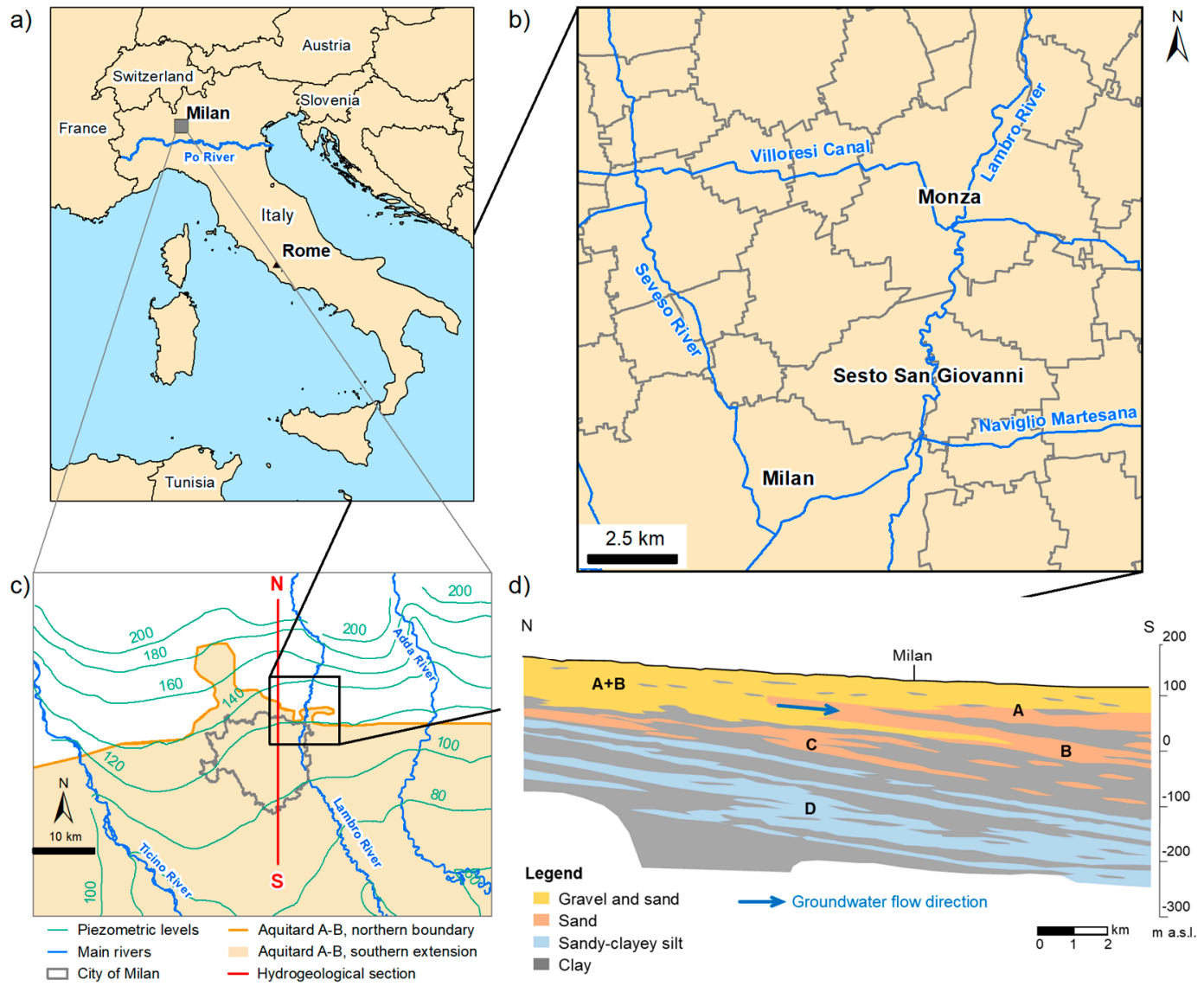

Figure 1. (a) Location of the study area (grey square); (b) study area with municipality borders, main rivers, and canals. Milan, Sesto San Giovanni, and Monza are the main cities in the study area. (c) Piezometric levels of the shallow aquifer ( $m$ a.s.l.). The golden line approximates the northern border of the aquitard: the main shallow aquifers ( $\mathrm{A}$ and $\mathrm{B}$ in the hydrogeological section) are hydraulically divided southwards (golden area), whereas the aquifers are not separated northwards $(A+B$ in the hydrogeological section); (d) north-south hydrogeological section.

The formation of the Po Plain basin occurred in a period of time extending from the Late Miocene into the Holocene [13-15]. The Milan plain subsoil consists of a succession of Pliocene-Pleistocene sediments which, in the superficial part, are mainly composed of gravel and sand of alluvial and alluvial-glacial origin, whereas in the basal part, they correspond to silts and clays of marine origin. The increase of clayey-silty fractions occurs not only with increasing depth, but also from the north to the south of the Milan plain. The presence of coarse deposits confined by finer fractions favors the protection of groundwater, which represents an essential resource that can supply the public, agricultural, and industrial requirements.

From a hydrogeological point of view, according to the classification system illustrated by Regione Lombardia and Ente Nazionale Idrocarburi [16], four aquifer groups can be identified in the plain area of the Lombardy region (Figure 1). In the study area starting from the top of the sequence, Group A corresponds to the shallow unconfined aquifer, and is mainly composed of coarse gravel and pebbles in a medium-to-coarse sandy matrix. It has an average thickness of $30-40 \mathrm{~m}$ and is characterized by high values of hydraulic conductivity (ranging from $10^{-4}$ to $10^{-3} \mathrm{~m} / \mathrm{s}$ ) and transmissivity (usually higher than $10^{-2} \mathrm{~m}^{2} / \mathrm{s}$ ). The underlying Group B consists of gravel and medium-coarse sand in a sandy matrix with discontinuous confining layers of clay and silt, limited to the lower part of the 
aquifer, that determine the presence of semi-confined and confined aquifers. Group B has a thickness of 50-60 m, and, due to the higher presence of clay and silt, it is characterized by lower values of hydraulic conductivity (ranging from $10^{-5}$ to $10^{-3} \mathrm{~m} / \mathrm{s}$ ) and transmissivity (ranging from $10^{-3}$ and $10^{-2} \mathrm{~m}^{2} / \mathrm{s}$ ) with respect to Group A. Group C and Group D contain the deepest aquifers, which were not analyzed in this study. The regional flow is mainly oriented north-south, and the groundwater depth decreases from north to south. In the study area, the groundwater depth of the shallow aquifer ranges between about $3 \mathrm{~m}$ and $50 \mathrm{~m}$ below the ground surface. In the northern sector of the plain, Group A and Group B constitute a unique shallow aquifer, whereas from the northern part of Milan southwards, the two aquifers are separated by an aquitard (thickness of $5 \mathrm{~m}$ and hydraulic conductivity of $10^{-8} \mathrm{~m} / \mathrm{s}$ ), of which the thickness and lateral continuity increase southwards [16-18]. This study focuses on the shallow aquifer, which is the one most exposed to the release of contaminants coming from the surface. This means we are considering data concerning the downgradient of Group A only with respect to the boundary of the aquitard, and the upgradient of both Group A and Group B with respect to the boundary of the aquitard (solid golden line in Figure 1).

The study area is one of the most urbanized and industrialized areas in Europe affected by chlorinated hydrocarbon contamination (i.e., tetrachloroethylene [PCE], trichloroethylene [TCE], and trichloromethane [TCM]). The area is characterized by two opposite trends in terms of land use changes. On the one hand, the main industrial activities have been dismissed and the land used for residential projects, which include the creation of new green areas. On the other hand, the urban area continues to increase, occupying former green and agricultural areas.

Recently, a hydro-chemical campaign was carried out by ARPA (Environmental Protection Regional Agency) in order to delineate plumes linked to PS and diffuse contamination not directly associated with a polluted site [17]. Cluster analysis [19-21] allowed researchers to identify, for the PCE dataset (more than 45,000 values are available from 2003 to 2014), the hot spots that were used as sources in a numerical transport model [22]. The contaminant transport model, calibrated with the 2014 concentration values, gave important information about the influence of the plumes on the groundwater chemical status observed in the monitoring well network.

The monitoring wells located inside the plume areas were removed from the contaminant concentration dataset, with the aim of keeping just the concentrations representing the multiple-point diffuse contamination component not related to specific known contaminant sources [22-25]. The new dataset (PCE median 2010-2014) was then used for analysis in this study.

\section{Materials and Methods}

\subsection{The WofE Modelling Technique: Classic and Alternative Approach}

Weights of evidence (WofE) is a cell-based modelling technique, which involves the combination of diverse spatial data that are used to describe and analyze interactions and generate predictive models $[26,27]$. It combines known occurrences of a phenomenon (training points, TPs, also called response variables) with the available spatial data (evidential themes, also defined as predictor factors or explanatory variables) in order to (a) perform an analysis of the influence that each factor has on the training points, and (b) generate a predictive response resulting from the combination of all the influencing factors and representing the spatial distribution of the occurrences in the study area. This technique has been successfully applied for mineral exploration [28,29], landslide hazard zonation [30,31], groundwater productivity potential [32,33], and groundwater vulnerability assessment $[7,8,34-36]$. Focusing on aquifer vulnerability, the procedure allows emphasis of the site-specific characteristics of the study area and avoids the use of the constant weight model in assessing the groundwater susceptibility [37]. In the last decade, the WofE modelling technique has been widely used in groundwater quality problems related to NPS, typically for nitrate contamination (i.e., classic approach, Figure 2; [7,8,34-36]). 
In this study, this methodology was performed using the Arc Spatial Data Modeler geoprocessing tools [38], and was applied to estimate groundwater susceptibility to PCE diffuse contamination using a classic approach as well as a re-adapted version (i.e., alternative approach, Figure 2).

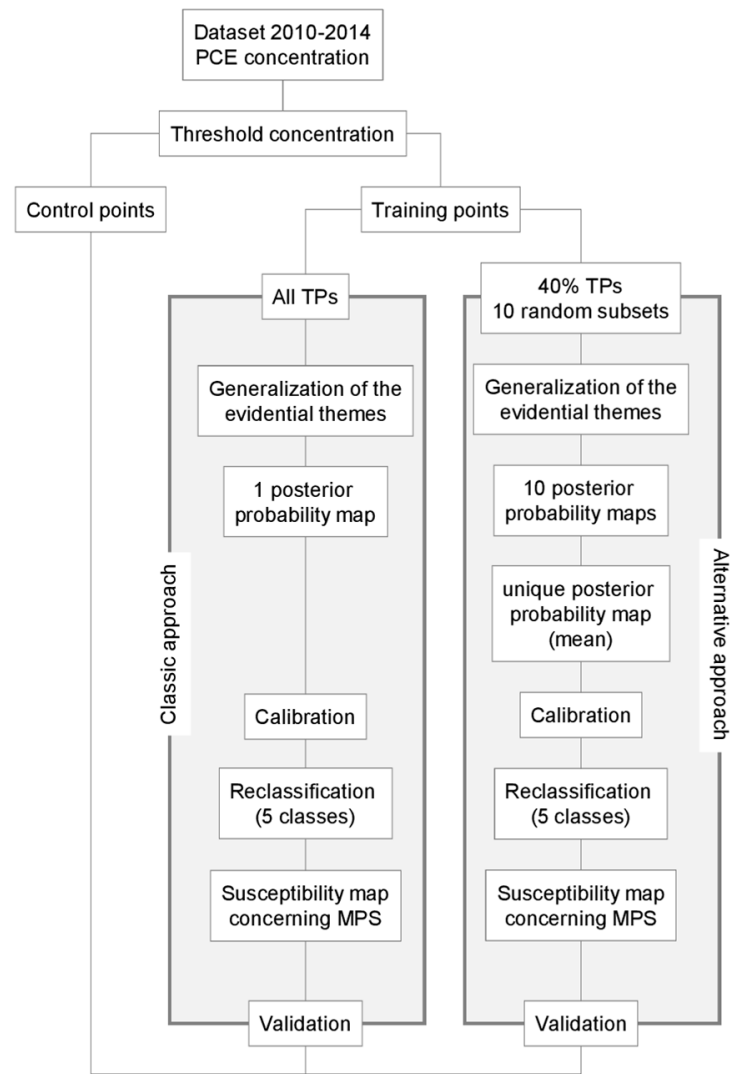

Figure 2. Flow chart representing the classic and the alternative Weights of Evidence (WofE) procedures.

As first step, a statistical analysis was performed on the water quality data associated with the monitoring wells in order to identify the most appropriate threshold [39] of PCE concentration values. This value has allowed us to distinguish (i) wells with concentrations above the selected limit, considered TPs and used to both generate and calibrate the final model, and (ii) wells with concentrations below the threshold value, identified as control points and used only during the validation procedure.

The classic approach was used to evaluate the robustness and reliability of the WofE method in accurately assessing the diffuse PCE contamination associated with MPS. The WofE uses a log-linear form of the Bayesian probability model, and is based on the concepts of prior and post probabilities. The prior probability indicates the probability that a cell within the study area contains a TP, independently of any existing predictor factor. It is obtained by the ratio between the number of cells containing TPs and the total number of cells representing the study area. The posterior probability is defined as the relative probability that a unit area contains a TP based on the evidence provided by the evidential themes. Relative probability means that areas with a higher posterior probability are more likely to contain TPs than areas with a lower one [26,29].

The definition of posterior probability is derived from the generalization of the evidential themes and the calculation of weights (positive and negative), contrast, and confidence values for each class of the evidential themes. The contrast, obtained by the difference between the positive and the negative weights, is a measure of the evidential theme's significance in predicting the location of TPs, and represents the overall degree of spatial association between each class of a given evidential theme and the occurrence of the phenomenon under investigation [26]. In particular, a positive contrast 
defines a direct correlation between the considered class and the occurrence of TPs, whereas a negative contrast indicates an inverse correlation between the considered class and the occurrence of TPs. The confidence level corresponds to the ratio between the contrast and its standard deviation, and provides a useful measure of the significance of the contrast [26,29]. In this study, a confidence value of 0.842 , corresponding approximately to an $80 \%$ level of significance, was selected as the minimum acceptable value to consider an evidential theme class as statistically significant. It also allowed us to identify the contrast values that could serve as breaking points to delineate the significant cumulative classes with a strong spatial association with high PCE concentrations.

Each evidential theme was repeatedly reclassified, reducing the number of statistically non-significant classes, and, using the categorical method, contrast and confidence values were calculated for all classes. The reclassification procedure applied in this study was based on that proposed and illustrated by Sorichetta et al. [40], and was designed to obtain the maximum number of statistically significant classes for each ordered evidential theme. The evidential themes that were both significant from a statistical and physical point of view were used to generate the predictive output. The first requirement means that the classes obtained from the generalization process respect the established level of significance, the second, that the same classes show a pattern distribution justifiable from a hydrogeological point of view.

The generalized evidential themes meeting the statistical and physical requirements were finally combined to generate a predictive output (i.e., a map) representing the distribution of the posterior probability values within the study area. The general quality of this map was evaluated by the area-under-the-curve (AUC) method. The AUC is a direct measure of the performance of the statistical approach, and is given by the area under the curve (integral) in a binary plot, considering the cumulated area/cumulated TPs expressed as a percentage [41]. The quality of the predictive output depends on both the AUC value and the shape of the curve. In particular, the higher the AUC value, the better the quality of the map, and the steeper the curve, the better the capability of the model to accurately describe the probability to find TPs within the study area.

After this calibration phase, the posterior probability map was reclassified into five classes through the geometrical interval method, which ensures that each class contains approximately the same number of different posterior probability values [42]. The reclassified probability map consists of five classes, each one reflecting a specific degree of susceptibility to diffuse PCE contamination, increasing from class 1 to 5 . Class 1 indicates the least susceptible areas, where the probability of finding a TP is very low, whereas class 5 corresponds to the most susceptible areas, where the probability of finding a TP is extremely high.

The reliability of this final susceptibility map was analyzed by adopting two statistical validation techniques, both described in previous studies [42,43], which included: (i) the frequency of training and control sets in each susceptibility class, and (ii) the average pollutant concentration in all wells located in each susceptibility class. Both these procedures were performed considering not only wells with a concentration higher than the threshold value (TPs), but also all the wells with a concentration lower than the threshold value (control points). The first method provides the frequency of TPs and control points for each susceptibility class. The frequency of TPs (or control points) is expressed as the ratio between the number of TPs (or control points) in a susceptibility class and the total number of wells in the same susceptibility class. The frequency of TPs and control points is expected to monotonically increase and monotonically decrease from susceptibility class 1 to 5 , respectively. The second validation procedure allows definition of the average pollutant concentration in all wells located in each susceptibility class. For each susceptibility class, the average concentration was derived from the ratio between the sum of concentration values measured in a susceptibility class and the total number of concentration data collected within the same susceptibility class. The average concentration should monotonically increase as the degree of susceptibility increases from class 1 to 5 .

The alternative approach was developed not only to assess groundwater susceptibility to diffuse PCE contamination, but also to obtain key information on the efficiency of the monitoring network 
in correctly discriminating among areas with a high degree of susceptibility and areas with a low degree of susceptibility to PCE pollution. Starting from the total number of TPs defined initially, ten random series were generated by selecting a small number of TPs $(40 \%)$ from the total training set. After assessing that each series showed a different spatial distribution of the TPs, the WofE technique was applied on each individual series using both the same the procedure and the same evidential themes adopted in the classic approach. This means that in each of the ten WofE models, all the evidential themes were generalized and reclassified by assuming a confidence value of 0.842 (i.e., $80 \%$ level of significance) to identify statistically significant contrasts and classes and the statistical and physical requirements were evaluated. Finally, ten posterior probability maps were obtained and then calibrated by applying the AUC technique. All these predictive outputs were combined to generate a unique posterior probability map, in which each cell contains the average posterior probability value calculated by considering the ten different posterior probability maps. This final map was reclassified into five classes, each one indicating a different degree of susceptibility to diffuse PCE contamination, increasing from class 1 to 5 . The performance of the reclassified map was tested by the application of the same validation techniques previously illustrated.

\subsection{Training Points}

For the purpose of this study, the TPs were associated with PCE concentrations in the groundwater. Data relating to PCE concentrations were collected by a network of monitoring wells distributed within the studied area. Starting from a network composed of 388 wells, only the 130 wells monitoring the unconfined aquifer within the study area were selected. Each one of these wells represented the median PCE concentration measured in the period 2010-2014 attributable to diffuse contamination that is not directly related to known contamination sources [11].

In the WofE modelling technique, the response variable (i.e., TP) is expressed in a binary form, establishing a threshold value to distinguish between occurrences and non-occurrences (a training and a control set, respectively). The histogram in Figure 3 shows the frequency of PCE concentration measured in the monitoring network. As shown by Masetti et al. [39], the most appropriate threshold value is independent from the frequency distribution and is given by the median value of concentration. Thus, the median value of $4.71 \mu \mathrm{g} / \mathrm{L}$ was adopted as the threshold to separate two different populations: wells (65) with PCE concentrations lower than $4.71 \mu \mathrm{g} / \mathrm{L}$, considered control points, and wells (65) with PCE concentrations higher than or equal to $4.71 \mu \mathrm{g} / \mathrm{L}$, used as TPs in the model. The training set was used to generate and calibrate the posterior probability map (i.e., predictive response), whereas the control set was used to validate the map obtained.

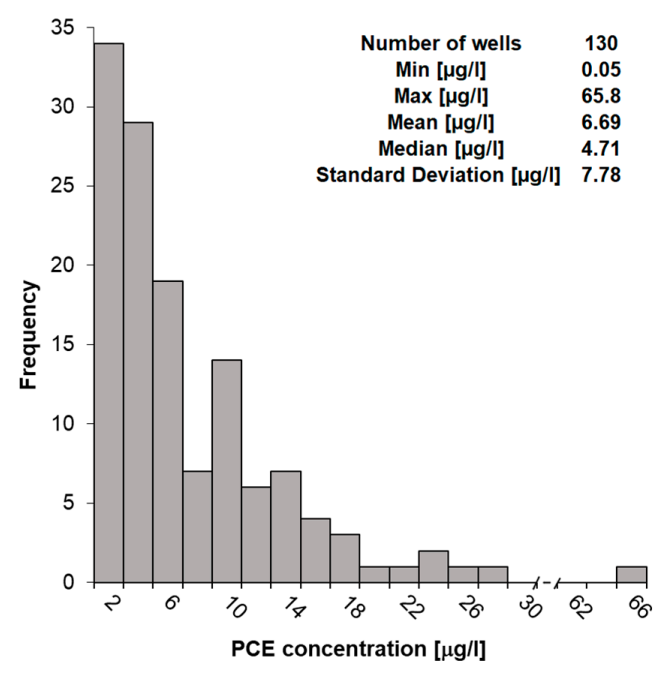

Figure 3. Frequency histogram of tetrachloroethylene (PCE) concentration. 
Instead of considering all of the resulting TPs, as in the past, in this study, ten series of TPs were derived by considering $40 \%$ of the TPs randomly selected from the total training set. This percentage of the total number allowed satisfaction of two conditions: (a) avoiding the repetition of similar TP distribution (generated when the percentage is too high), and (b) maintaining an adequate number of TPs, necessary to perform a reliable statistical analysis (unachievable when the percentage is too low).

\subsection{Evidential Themes}

The WofE methodology is performed on a raster basis and requires that evidential theme maps are derived using the same unit cell size. A unit cell of $0.25 \mathrm{~km}^{2}$ was used for both the thematic and final maps. In this analysis, the occurrence of high PCE concentrations in groundwater within the study area was related to both natural and anthropogenic factors. Five explanatory variables were chosen as evidential themes in all ten WofE models (Figure 4):

- groundwater depth,

- hydraulic conductivity of the vadose zone,

- groundwater velocity,

- percentage of "potential sources zone" (PSZ) extent in 2000, including industrial, artisanal, and commercial settlements,

- $\quad$ PSZ variation during the period 2000-2012.

Groundwater depth was selected as an evidential theme, considering that the near-surface groundwater table decreases the vertical distance through which the contaminant must travel before reaching groundwater. The groundwater depth map of the shallow aquifer was created by calculating the difference between the topographical level and the groundwater piezometric level; the latter was generated by kriging interpolation with trend analysis of the piezometric measurements [44]. In the study area, the groundwater depth ranges from 3 to $52 \mathrm{~m}$. High values occur in the north-western sector, and gradually decrease moving to the south-east sector.

The hydraulic conductivity of the vadose zone was included in the WofE analysis for its role in controlling the contaminant travel time through the vadose zone. The hydraulic conductivity of the vadose zone comes from a map obtained by interpolating some experimental data from borehole tests together with values derived from well stratigraphy records through the equivalent vertical permeability method [45], considering the thickness of the layers in the vadose zone. The hydraulic conductivity of the vadose zone ranges from $1.9 \times 10^{-8}$ to $5.7 \times 10^{-2} \mathrm{~m} / \mathrm{s}$, and in general, its distribution is rather irregular in the study area.

Groundwater velocity was chosen as evidential theme, considering its influence on the movement of the contaminant within the aquifer, in terms of transport and dilution processes. The groundwater velocity was determined using the hydraulic conductivity data obtained from pumping tests, together with the local hydraulic gradient. The groundwater velocity ranged from $7.2 \times 10^{-7}$ to $1.3 \times 10^{-5} \mathrm{~m} / \mathrm{s}$. Higher values occupy a portion of territory which extends from the north-western sector to the central part of the study area.

Since, in densely urbanized areas, the high presence of human activities has been recognized as the main cause responsible for diffuse PCE contamination, this analysis considered the extent of anthropogenic activities related to chlorinated solvent use and their change over time as potential sources of groundwater pollution. The land use maps were derived from those prepared by the Agency of Services of Agriculture and Forest, as part of the regional land use inventory called DUSAF [46]. The first version of this database was created in 2000 by the interpretation of high-resolution aerial photographs taken in 1998-1999, and it is updated periodically at irregular intervals. The DUSAF inventory is based on a legend articulated on many levels, each of which represents a specific land use class according to the land cover characteristics of the territory. Industrial activities, such as automotive, refineries, chemical plants, stills, and tire production, are potential sources of PCE contamination in groundwater. Areas characterized by the presence of these activities are categorized in the DUSAF 
inventory in the class "industrial, artisanal and commercial settlements," identified by the code "12111" and representing PSZ. The PSZ extent is calculated as the percentage of areas occupied by the 12111 class in each $0.25 \mathrm{~km}^{2}$ cell. To take into account the influence of both the groundwater flow direction and the impact of PSZs located upgradient of each cell, a procedure called focal method was applied. The algorithm in the focal method considers both the value of each cell and the values of the surrounding cells with a deterministic mathematic function (i.e., arithmetic mean). By using this technique, it was possible to recalculate the percentage of PSZ extent in each cell by assigning the mean of the values in the surrounding cells located upgradient. As shown in Figure 5, among the surrounding cells, only the cells contained in a buffer of $250 \times 550 \mathrm{~m}$ (colored in light blue) were considered in the calculation.

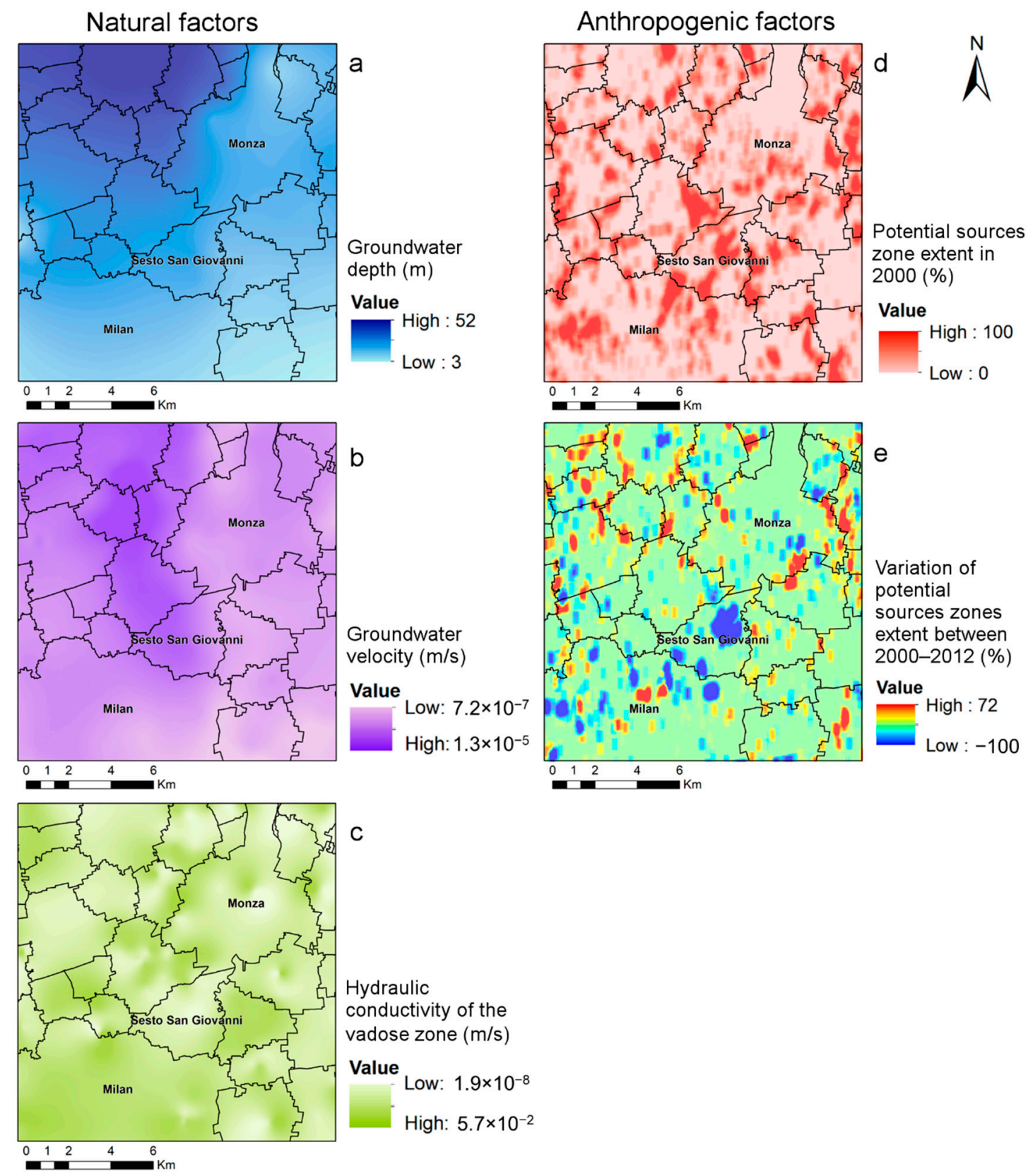

Figure 4. Natural and anthropogenic factors influencing groundwater contamination: (a) groundwater depth; (b) groundwater velocity; (c) hydraulic conductivity of the vadose zone; (d) potential sources zone (PSZ) extent in 2000; (e) variation of PSZ extent between 2000 and 2012. 
Two maps were generated: the first representing the distribution of PSZs in 2000 (DUSAF version 1.1), and the second corresponding to the variation of the percentage of PSZs between 2000 and 2012 (DUSAF version 4.0). The latter was obtained by calculating the difference between the PSZ percentages in 2012 and in 2000. Positive values indicate an expansion of PSZs, while negative values indicate a reduction of PSZs. According to DUSAF data, the PSZ extent changed in the range of -100 to $+72 \%$.

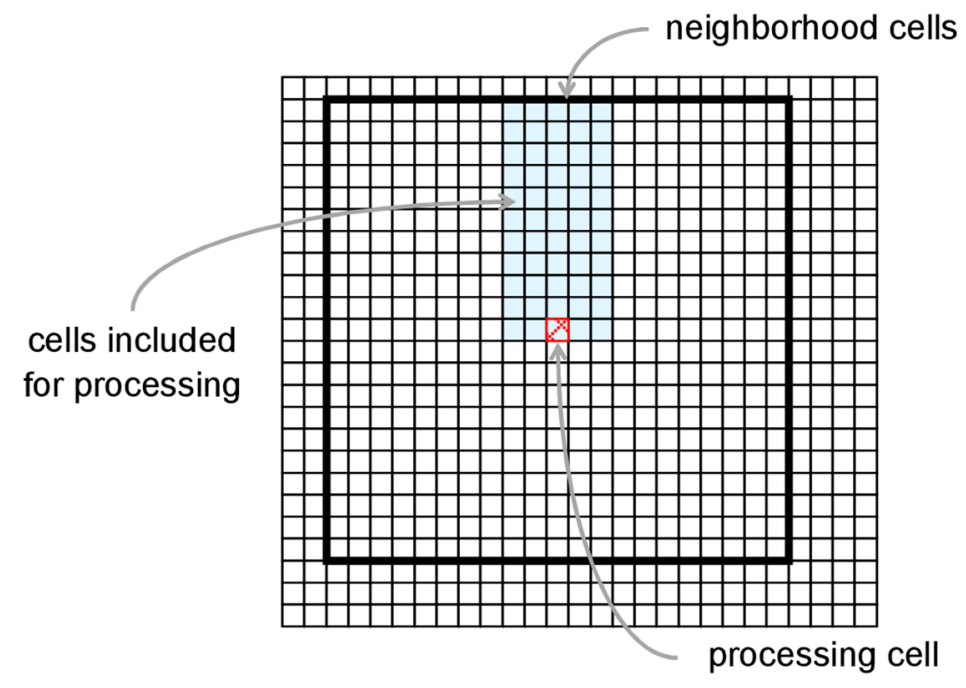

Figure 5. Focal method. Each cell is a $50 \mathrm{~m} \times 50 \mathrm{~m}$ square $\left(0.25 \mathrm{~km}^{2}\right)$. Cells colored in light blue correspond to those considered in the calculation of the mean percentage of PSZ extent, attributed to the cell colored in red.

\section{Results}

\subsection{Contrasts of the Generalized Evidential Themes}

In all the ten WofE models, the same types of correlations were found between each generalized evidential theme and the occurrence of PCE contamination. As represented in the graphs in Figure 6, obtained from one of the WofE models, groundwater velocity, hydraulic conductivity of the vadose zone, and percentage of PSZ extent in 2000 showed a general direct relationship between the highest values of the evidential themes and the diffuse PCE contamination. Groundwater depth was characterized by an inverse correlation between the highest values of the variable and the occurrence of TPs, whereas the variation of the percentage of PSZ extent in 2000-2012 showed a direct correlation between the lowest and highest values of the variable and high PCE concentrations.

\subsection{Predictive Responses and Susceptibility Map}

After defining the contrasts, ten predictive responses consisting of ten posterior probability maps were generated. They were obtained by the combination, in each WofE model, of all five statistically and physically significant evidential themes described above. In this study, the result of the whole analysis was represented by a unique posterior probability map, in which the value of the posterior probability for each cell is the mean of the ten values obtained in the different predictive models.

This model probability output was reclassified to generate a map consisting of five classes, each reflecting a specific degree of susceptibility (Figure 7a): the susceptibility increases from 1 (very low) to 5 (extremely high). 

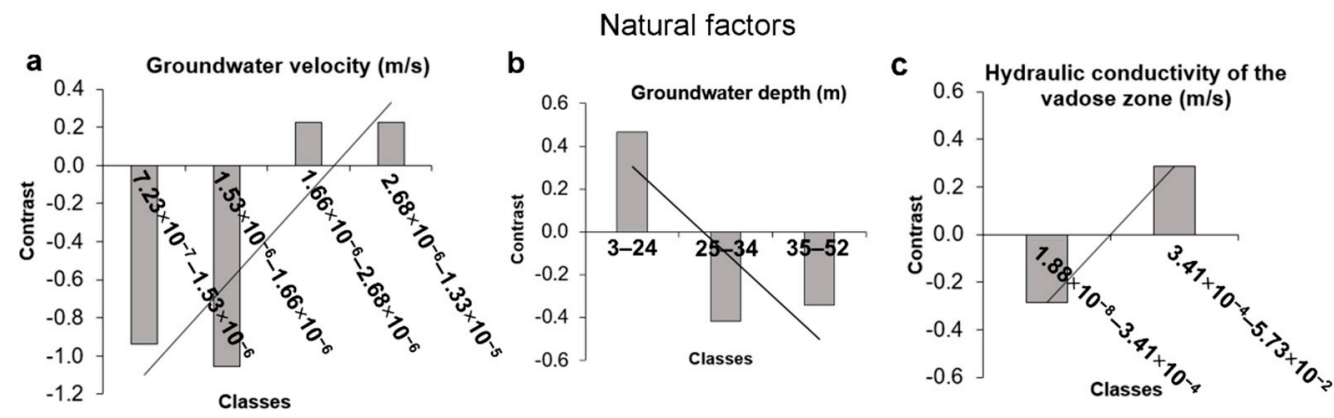

Anthropogenic factors
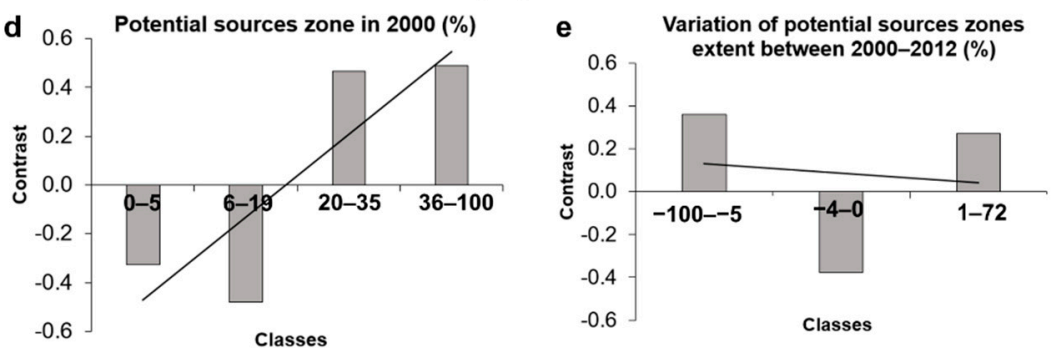

Figure 6. Contrasts of the statistically significant classes of each evidential theme: (a) groundwater depth; (b) groundwater velocity; (c) hydraulic conductivity of the vadose zone; (d) PSZ extent in 2000; (e) variation of PSZ extent between 2000 and 2012.
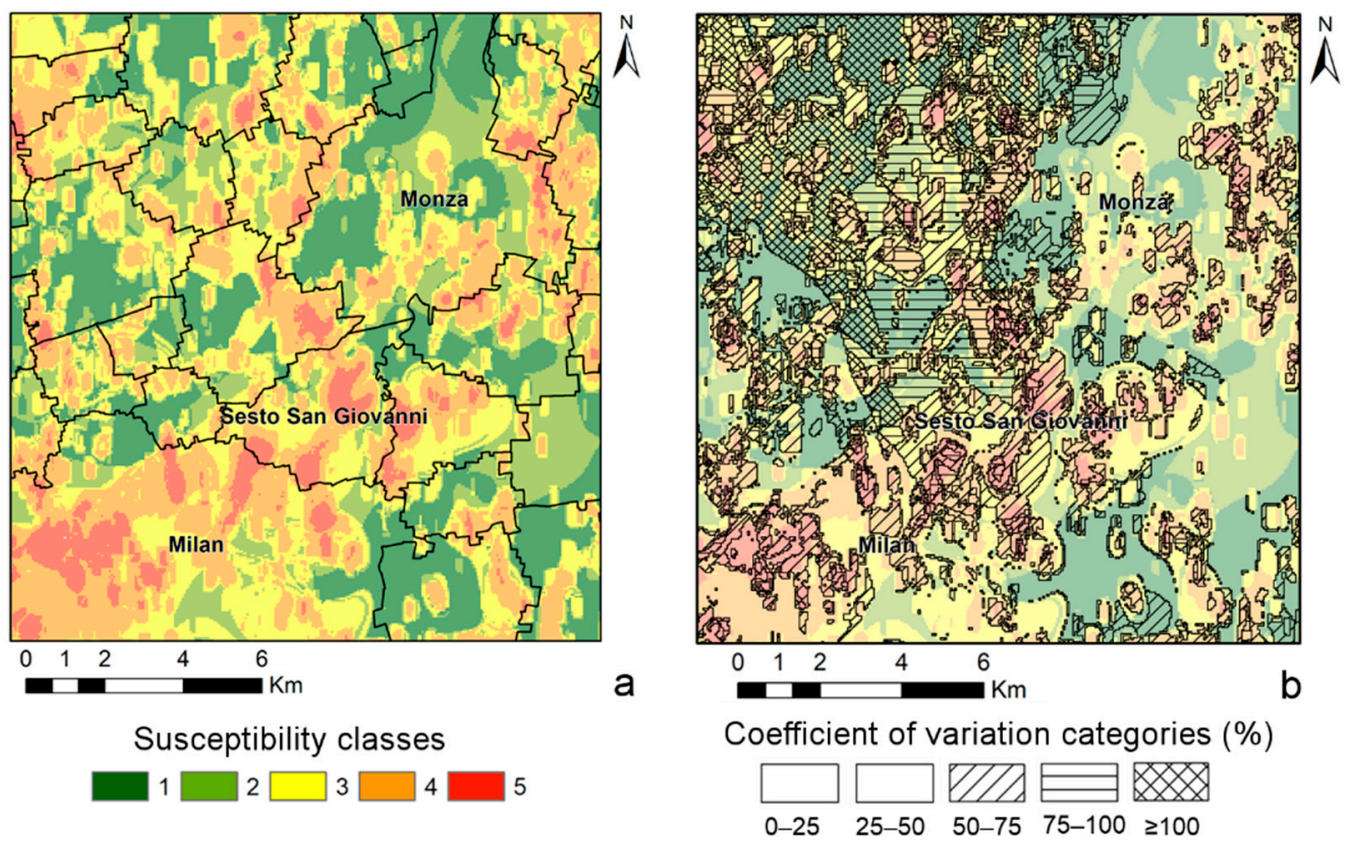

Figure 7. (a) Map representing the distribution of susceptibility classes within the study area; (b) map representing the coefficient of variation (\%) overlaid on the susceptibility map (in transparency). The degree of susceptibility increases from green (class 1) to red (class 5) colors.

In order to examine the quality of the final predictive map, a degree of uncertainty was associated with each mean posterior probability value. This allowed us to evaluate the dispersion of the values that were reasonably attributable to each mean posterior probability value, which was defined by the coefficient of variation $(\mathrm{CV})$, obtained by the ratio between the standard deviation and the absolute value of the mean posterior probability. This means that high values of the coefficient of variation reflect a high dispersion of the values around the mean value and, consequently, a high uncertainty. 
The map representing the coefficient of variation was reclassified into five categories, each corresponding to a specific range of CV values expressed as a percentage: $0-25 \%, 25-50 \%, 50-75 \%$, $75-100 \%$, and $\geq 100 \%$. This categorized map was overlaid on the susceptibility map to identify zones with a high degree of uncertainty within the study area (Figure $7 \mathrm{~b}$ ). As represented in Table 1, 50\% of the study area is characterized by a percentage CV below 50\%, indicating a dispersion of the posterior probability values around the mean value lower than the half of the mean posterior probability value. Moreover, only $10 \%$ of the total area shows a CV value higher than $100 \%$, with the smaller areas corresponding to the highest susceptibility degrees (classes 4 and 5).

Table 1. Percentages of area covered by each susceptibility class and each category of coefficient of variation within the study area.

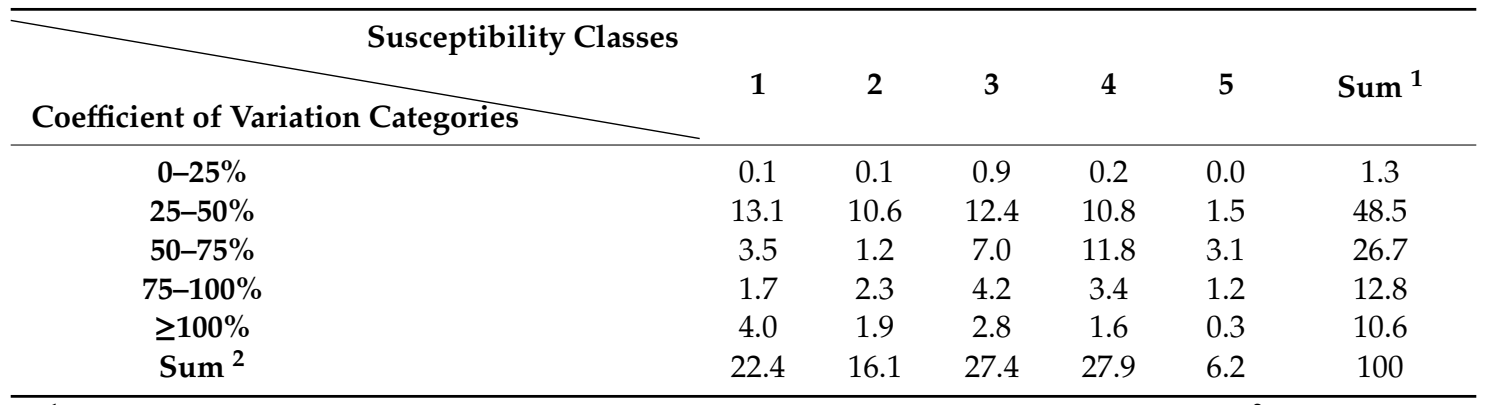

${ }^{1}$ Sum of areas corresponding to the same category of coefficient of variation (in percentages). ${ }^{2}$ Sum of areas corresponding to the same susceptibility class (in percentages).

\subsection{Reliability and Validation}

As represented in Figure 8a, the AUC technique was applied on each posterior probability map, providing an overall value greater than $68 \%$ and indicating a good quality of the maps.

\begin{tabular}{|c|c|}
\hline WofE models & AUC (\%) \\
\hline W1 & 68.1 \\
W6 & 69.1 \\
W7 & 69.2 \\
W10 & 69.2 \\
W3 & 69.5 \\
W5 & 71.0 \\
W4 & 72.2 \\
W8 & 72.3 \\
W9 & 75.1 \\
W2 & 75.7 \\
\hline
\end{tabular}

C

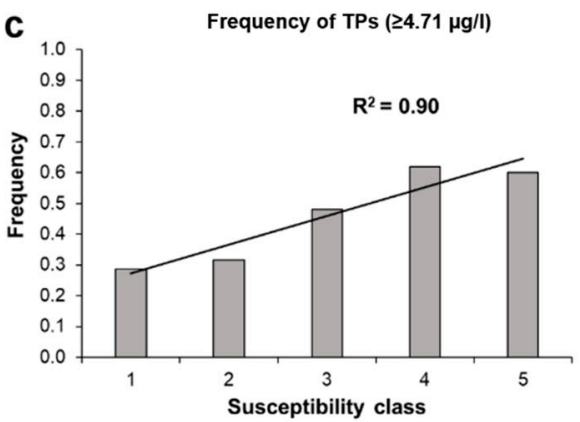

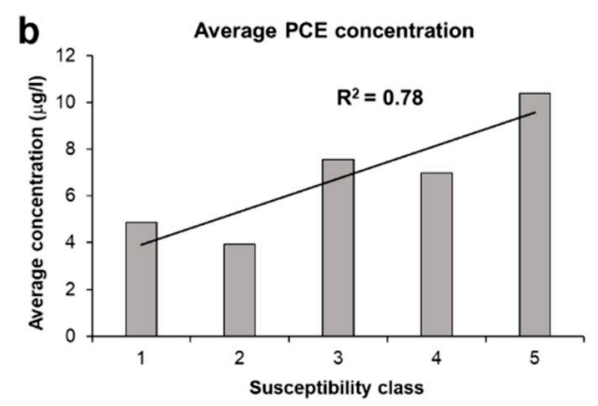

d

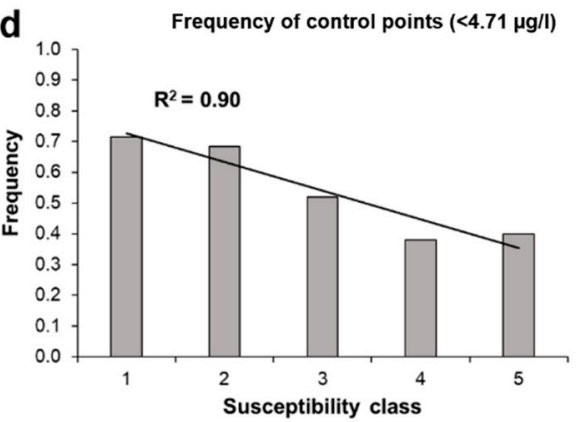

Figure 8. (a) area-under-the-curve (AUC) values for the ten post probability outputs. Histograms of the average PCE concentration (b), the frequency of the training points (c), and the control points (d) in each susceptibility class of the map in Figure 6a. The susceptibility increases from class 1 to class 5 .

The performance of the reclassified susceptibility map was analyzed by defining the average PCE concentration and the frequency of TPs and control points in each susceptibility class. The histogram 
derived from the average concentration technique (Figure 8b) showed that, as expected, the average PCE concentration increased according to the degree of susceptibility with a high regression coefficient value $\left(R^{2}=0.78\right)$. Nevertheless, this validation method pointed out some anomalies related to class 2 , characterized by an average concentration value lower than class 1 , and to class 4 , showing an average concentration value lower than class 3 .

Histograms obtained from the frequency of TPs and control points (Figure 8c,d) highlighted that, consistently with the previsions, the frequency of training and control points monotonically increased and monotonically decreased from susceptibility class 1 to 5 , respectively, with a high regression coefficient value $\left(R^{2}=0.90\right)$. In this case, class 5 represents an anomaly, since it is characterized by a frequency of TPs lower than class 4 (Figure $8 \mathrm{c}$ ) and by a frequency of control points higher than class 4 (Figure 8d).

\subsection{Evaluation of the Efficiency of the Monitoring Network}

The posterior probability map, obtained from the mean of the ten predictive models, was used to perform further analysis. Considering the total number of TPs obtained initially (65), the classic WofE method was applied and a predictive model was generated. As in the analysis with the ten WofE models, this predictive response was created by establishing a level of significance equal to $80 \%$ and adopting the same five statistically significant evidential themes. Additionally, in the classic WofE model, the same correlations between each evidential theme and the occurrence of TPs were found.

The post probability maps derived from these two different approaches of the WofE technique were then combined by calculating the difference between the post probability map generated with all TPs (i.e., classic approach) and the map obtained by the ten random series of TPs (i.e., alternative approach). The resulting post probability value, called the "delta post probability," permitted us to identify specific TPs that proved to be the most influential in the analysis. This was made possible by examining the peaks resulting in the histogram obtained by plotting all 65 TPs on the X-axis and the delta post probability values on the Y-axis (Figure 9).

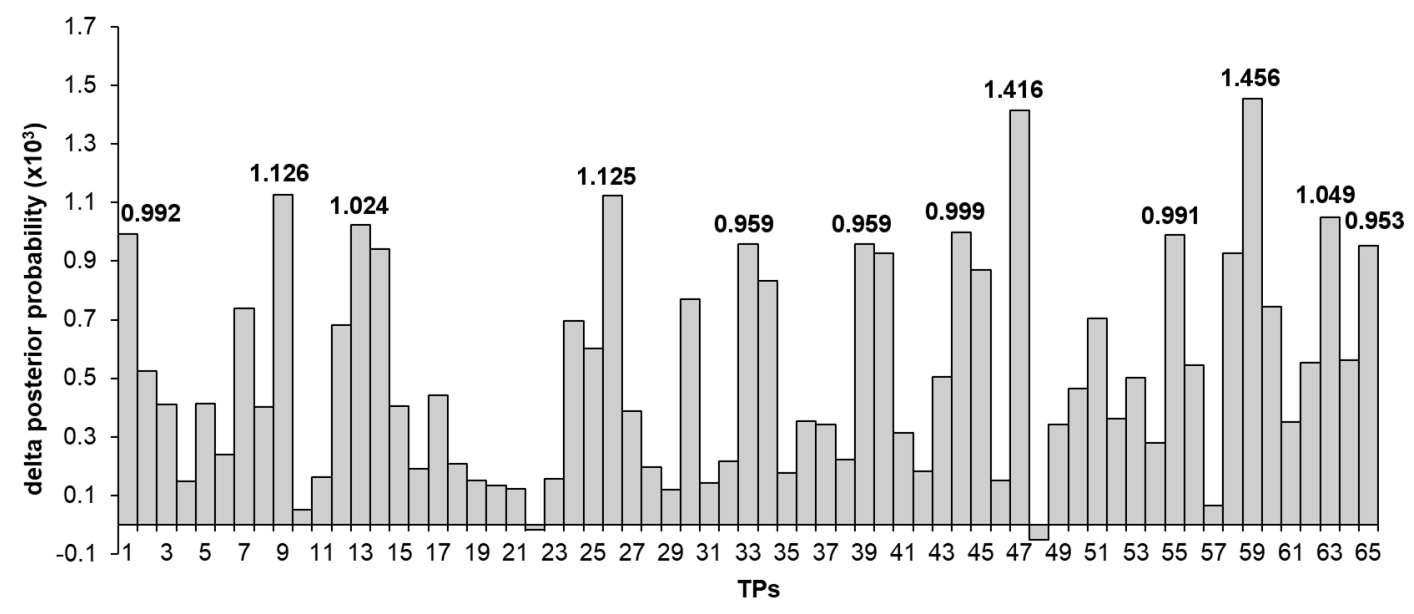

Figure 9. Histogram representing the most influential training points (TPs), corresponding to the peaks highlighted by the highest values of the delta post probability.

Since each monitoring well is representative of the environmental characteristics of its surroundings, the post probability values in a radius of $100 \mathrm{~m}$ in and around each TP were considered when calculating the delta post probability. With this graphic procedure, 12 TPs were identified, associated with high delta post probability values. It is interesting to note that the most influential TPs were located in the areas with the highest degree of susceptibility (Figure 10). This highlights the importance of these TPs in the analysis, since their presence or absence caused a great variation of post probability values. On the other hand, most of the TPs were associated with small values of the delta post probability, 
meaning that their presence or absence was less influential in the analysis. The less influential TPs were not related to a particular degree of susceptibility.

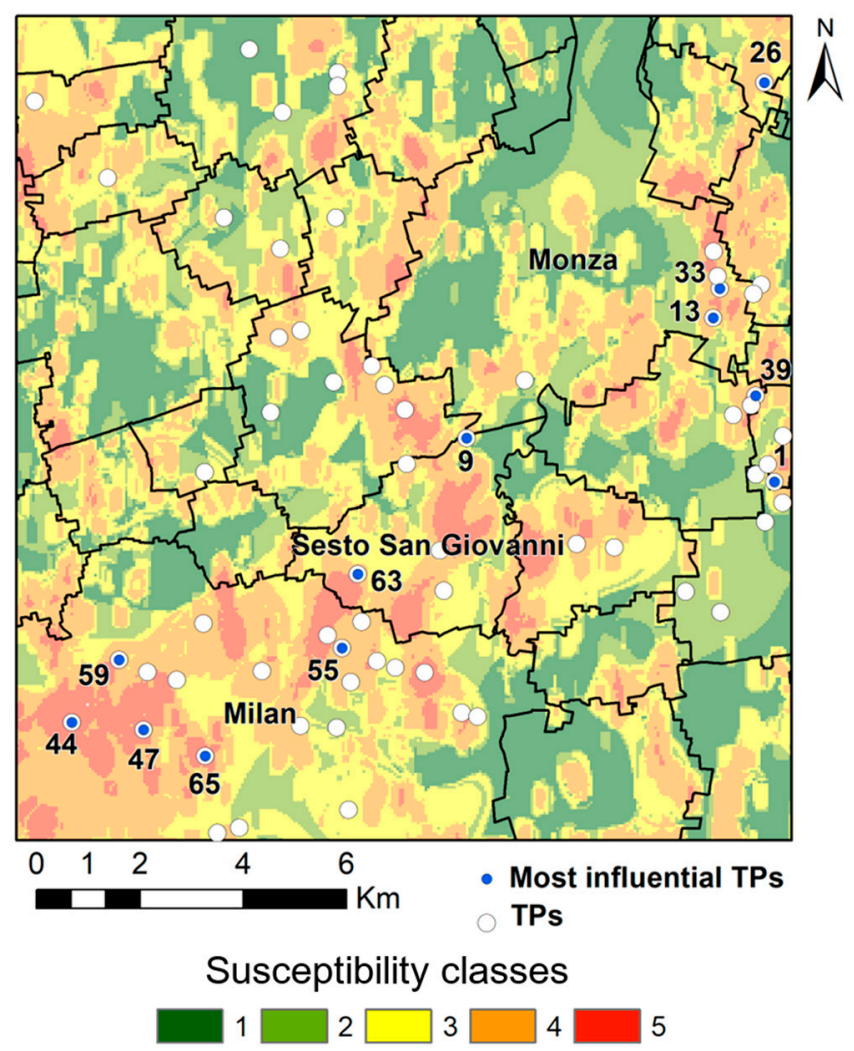

Figure 10. Location of the most influential TPs (blue dots) in the study area, overlaid on the susceptibility map (in transparency). Susceptibility degree increases from green (class 1) to red (class 5) colors.

\section{Discussion}

Contrast values obtained for each statistically significant class of evidential themes made it possible to analyze the influence of each factor in the distribution of groundwater PCE contamination in the study area. To perform a susceptibility analysis with the WofE technique, it is necessary that the evidential themes, considered as inputs, have a statistical, but also a physical, significance. Therefore, it is important to find a possible explanation that can be used to justify and interpret each type of correlation, resulting in the analysis between each variable and the PCE contamination.

Both evidential themes representing the groundwater velocity and the unsaturated hydraulic conductivity showed a direct correlation between PCE contamination and the highest values of each predictor factor. This result is related to the influence of these two hydrogeological variables on the movements of contaminants from the surface to the aquifers. High values of hydraulic conductivity of the vadose zone suggest the presence of coarse deposits that can hardly represent a natural obstacle to the migration of the contaminant towards the deep strata. In sectors of high groundwater velocity, the contaminant transport process generally dominates over the dilution process, causing distribution of the contaminant over large areas.

The evidential theme corresponding to the groundwater depth showed a direct relationship between the lower values of the variable and high PCE concentrations. Low values of groundwater depth indicate that the piezometric level is close to the topographic surface. Obviously, in areas where this condition occurs, the probability of PCE contamination increases, because the contaminant can reach the shallow aquifer more easily. 
In addition to these natural variables, anthropogenic factors were also used, considered as potential sources responsible for the release of PCE. The evidential theme representing the percentage of PSZs in 2000 showed a positive correlation between the highest values of the variable and the PCE contamination. This means that the probability of finding high PCE concentrations increases where areas are more urbanized, in terms of the presence of industrial activities. This result is consistent with that expected, because PCE, and chlorinated solvents in general, have been used for several years in industrial processes, for example as degreasers. An interesting result was obtained from the analysis of the contrasts of the evidential theme corresponding to the variation of the percentage of PSZs between 2000 and 2012. It showed a direct relationship between classes 1 ( -100 to $-5 \%)$ and $3(1$ to $72 \%)$, representing a significant variation of the percentage of PSZs and PCE contamination, whereas class $2(-4$ to $0 \%$ ), corresponding to small or zero variations of PSZs, was indirectly correlated to high PCE concentration. This result needs further analysis in order to better understand its meaning.

As previously discussed, the variable related to the percentage variation of PSZs between 2000 and 2012 was generated by the difference between the percentage of PSZs in 2012 and that in 2000. Nevertheless, it is important to consider that a value of the variation of PSZs equal to zero does not necessarily represent the absence of PSZs in both years. This occurs when, for example, an area characterized by a percentage of PSZs corresponding to $50 \%$ in 2000 also shows the same percentage $(50 \%)$ in 2012. In this case, the result obtained by the difference between the percentage of PSZs in 2012 and in 2000 would be equal to zero, despite the existence of a potential source of contamination within the urban areas. Therefore, a variation of PSZs equal to zero could indicate either their total absence in 2000 and 2012, or the same amount of PSZs percentage in both years.

In order to evaluate which of these two possibilities explained the zero value in this analysis, a mask was created within the map, representing the variation of PSZs between 2000 and 2012 by discriminating the area occupied by class 2 ( -4 to $0 \%$ ). The mask containing class 2 was then overlaid with the map related to the percentage of PSZs in 2000. The combination of the two maps showed that $40 \%$ of the area occupied by class 2 was characterized by a percentage of PSZs corresponding to zero, due to the effective absence of PSZs in both 2000 and 2012. Thirty-five per cent was characterized by a small percentage of PSZs in the year 2000 (less than 15\%), whereas only $6 \%$ was occupied by potential sources of contamination in 2000, and, thus, the area was subjected to a complete reduction of PSZs in the decade of the 2000s.

The overall result of the variation of PSZs between 2000 and 2012 suggests that PCE contamination is directly related to the areas that, in past or recent times, have hosted anthropogenic activities responsible for the release of PCE. This indicates the coexistence of (1) a "historical" contamination, mainly due to the presence of former extended industrial areas that have been transformed into residential zones (negative percentage PSZ change values), and (2) a "younger" contamination, mainly due to the more recent increase of urban areas in former green zones (positive percentage PSZ change values).

Using and combining all the evidential themes described above, a map representing the degree of susceptibility to diffuse PCE contamination was prepared. The obtained susceptibility map was categorized from class 1 (very low degree of susceptibility) to 5 (extremely high degree of susceptibility), and allowed us to identify the areas most responsible for high PCE concentrations (Figure 7a). The map shows that $39 \%$ of the study area is attributed to classes 1 and 2,27\% to class 3 and $34 \%$ to classes 4 and 5. Moreover, the most impacted sector is located in the south-west part of the study area and mainly involves the municipalities of Milan and Sesto San Giovanni.

Evaluating the individual role of each evidential theme, the anthropogenic factors seem to be powerful in discriminating among susceptible and not susceptible areas. This can be inferred by observing the shape assumed by areas with a high susceptibility (classes 4 and 5 of the map in Figure 7a). In fact, it is comparable to the shape of strongly "urbanized areas" in 2000 (Figure 4d), or to the shape of areas that have hosted PSZs between 2000 and 2012 (Figure 4e). 
The reliability of the susceptibility map was evaluated by applying the frequency and average concentration procedures, and by examining the regression coefficient (Figure 8). Despite some anomalies in the histograms, the results obtained from both validation techniques, together with the high values assumed by the regression coefficient, suggest that the final susceptibility map can be considered reliable.

The alternative approach of the WofE technique enables the evaluation of the reliability of the final map by calculating the distribution of the coefficient of variation. It is defined as the ratio between the standard deviation and the absolute value of the mean posterior probability, and represents the degree of uncertainty. Overlaying this map with the susceptibility map (Figure $7 \mathrm{~b}$ ) allows us to identify the areas characterized by a high degree of uncertainty. The sector with the highest degree of uncertainty is located along a portion of territory that extends from the north-west to the central part of the study area.

This analysis, together with the susceptibility map and the definition of the most influential TPs (Figure 10), could provide extremely effective information for some practical applications. For example: (i) the identification of the areas most exposed to PCE contamination, (ii) the determination of the zone with a high degree of uncertainty, and, finally, (iii) the recognition of wells with a high relevance for diffuse contamination detection could offer numerous useful data in the context of the correct design of a monitoring network. The first two analyses ( $\mathrm{i}$ and ii) could indicate the areas where it would be necessary to increase the number of monitoring points in order to intensify the investigations of the evolution of the contamination. The last analysis (iii) could help in the identification of the control points that must be preserved in case of a possible reduction of the monitoring network.

\section{Comparison between the Spatial Statistical Approach and the Numerical Stochastic Approach}

The last part of this study provides the comparison between the final susceptibility map generated with the WofE technique (i.e., alternative approach), and the results of the groundwater flow and advective transport model, produced using an advanced Monte Carlo method in the analysis carried out by Alberti et al. [11] that is briefly summarized here.

The authors used particle tracking in an advanced version of the Monte Carlo approach called the Null Space Monte Carlo (NSMC; [47]) to identify areas vulnerable to diffuse anthropogenic pollution.

The "null space" contains parameters that are not well constrained by field data and provide an equally valid calibration, but which, nevertheless, have significant effects on model predictions. Starting from a deterministic model and using the NSMC procedure, stochastic model processing was used in order to randomly generate a high number $(>100)$ of different realizations of the hydraulic conductivity influencing the travel path of contaminants. Only those realizations that provided a satisfactory fit to the observed heads were kept (i.e., calibrated models). The variability in the parameter fields returns the uncertainty of the system knowledge that reflects on the system representation in the model. This variability was translated into differences in the distribution of the simulated heads, and hence in the paths advectively followed by contaminants. It was then possible for each realization to backtrack particles from those monitoring wells that showed concentrations over a certain threshold $(10 \mathrm{mg} / \mathrm{L})$.

Considering the uncertainty associated with the hydrogeological parameters, the path-line directions simulated in each of the one hundred runs differed for the same particle starting location because of the different parameter fields generated with the NSMC procedure. By computing the number of particles crossing each model cell in all of the generated simulations, it was possible to obtain maps of the occurrence frequency of the particle path. The higher the frequency in a model cell, the higher the probability that the cell contains MPS responsible for the observed concentrations. The density of the resulting particle traces was then interpreted as the probability of the occurrence of multiple pollution sources.

This comparison required two modifications of the WofE model: (a) the reduction of the size of the study area (by about $50 \%$ ), and (b) the conversion from a posterior probability to a normalized posterior probability. The latter was obtained by the ratio between each posterior probability value 
and the maximum posterior probability value. This conversion was necessary to make the two types of probability derived from the two different methodologies comparable. In the model generated with the NSMC analysis, the probability (expressed as a percentage) of the occurrence of multiple pollution sources is associated with the frequency of particles passing through each cell within the study area. In the WofE method, the posterior probability is not represented by percentage values and corresponds to a relative probability. This means that it is only valid within the study area, and, thus, zones with a higher posterior probability are more likely to be exposed to high PCE concentrations than zones with a lower one (Section 3.1). The normalization of the posterior probability allowed us to overcome the concept of relative probability and express the probability values as a percentage.

Both maps were categorized into four classes, each associated with different ranges of percentage values (Figure 10$)$ : class $1(<0.1 \%)$, class $2(0.1$ to $0.25 \%)$, class $3(0.25$ to $0.50 \%)$, and class $4(>0.50 \%)$. In the NSMC model, classes 1 and 4 correspond to the low and high probability that each model cell hosts sources responsible for diffuse PCE contamination, respectively (Figure 11a). In the WofE model, each class reflects the likelihood of having active MPS, which increases from class 1 to 4 and depends on the presence of both anthropogenic activities and specific hydrogeological conditions (Figure 11b).

The comparison between the two maps reveals a general agreement in the distribution of the areas strongly exposed to PCE contamination: in both maps, the central sector of the study area corresponds to the most critical part of the territory. Nevertheless, the map generated with the WofE method shows a greater occurrence and extent of the most problematic areas with respect to the NSMC model, also involving the south-western and the eastern sectors of the study area.
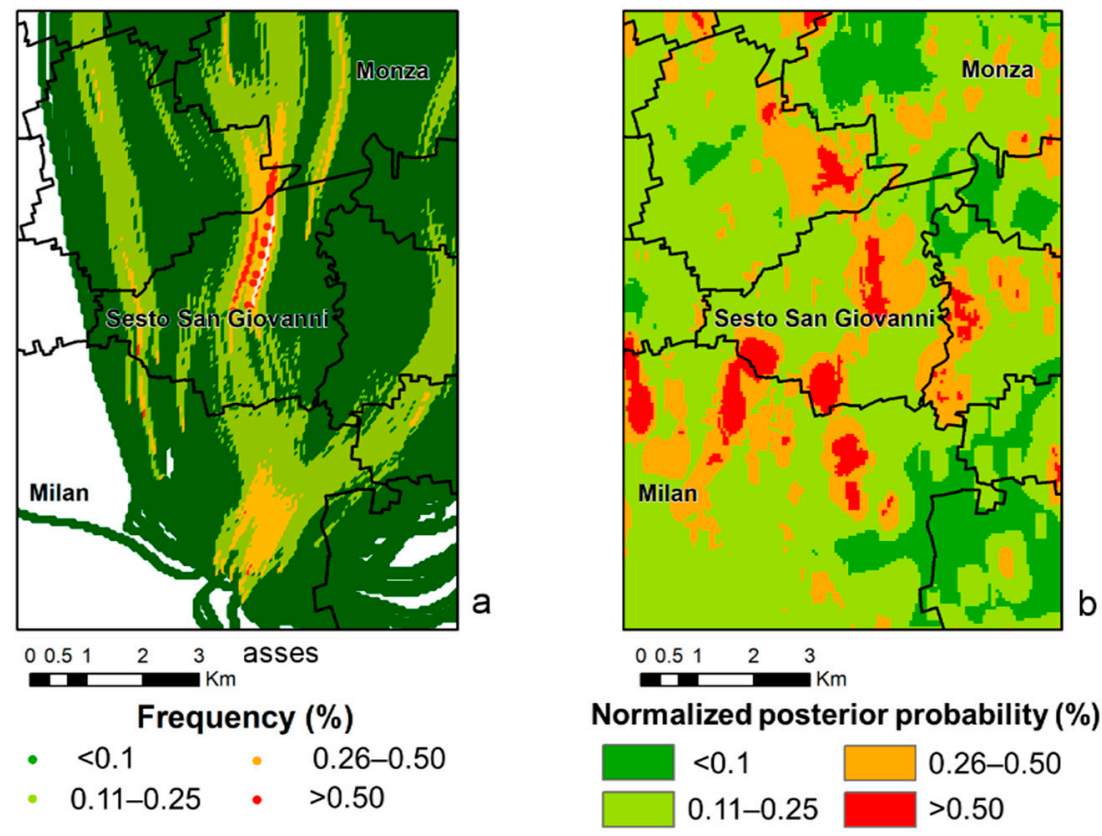

Figure 11. Map (a) represents the contributing diffuse contamination areas defined by the occurrence frequency of particles backtracked within the study area. High percentages of frequency express a high probability of finding sources responsible for diffuse PCE contamination (red areas). Map (b) shows the distribution of the normalized posterior probability. High percentages of normalized posterior probability correspond to a high degree of susceptibility (red areas).

\section{Conclusions}

The presence of an anthropogenic diffuse contamination in FUAs is an environmental management issue that is becoming more and more relevant. Public bodies feel the need for tools able to support them in the management of this issue through the planning of policies and actions such as investigations, monitoring, and allocation of areas mostly responsible for the diffuse contamination status. To face 
these aspects requires the development and assessment of new methodologies of statistical analysis and numerical modelling able to consider the concentration data, hydrogeological properties, and relevant anthropogenic pressures.

The methodology presented here follows a Bayesian approach that has already been successfully applied to diffuse contamination linked to NPS. The use of an alternative approach was validated, showing that the method can be efficiently used to:

- $\quad$ spatially evaluate the likelihood of having active MPS in a contaminated groundwater area;

- relate their impact on the shallow aquifer to the hydrogeological features of the area;

- highlight the presence of diffuse contamination due to both "historical" (that is, already removed) and recent MPS;

- test the efficiency of the monitoring network in properly characterizing the contamination in the aquifer, both for reducing the uncertainty in identifying the contaminated area and for eliminating unnecessary monitoring points.

As a double check, the results were compared with those obtained through an existing inverse numerical modelling approach within a Monte Carlo statistical framework [11]. The comparison was positive, showing a good agreement between the two approaches in identifying almost the same areas as having the highest likelihood of hosting MPS. This result is very promising for the future combination of the two approaches in targeting investments for groundwater management related to contamination problems. The approaches can be jointly used to minimize the uncertainties in this environmental issue, to further improve the identification of FUAs that most probably contain MPS.

Author Contributions: Conceptualization, M.M. and L.A.; methodology, L.C.P., M.M. and S.S.; formal analysis, L.C.P.; data curation, L.C.; writing-original draft preparation, L.C.P., S.S., and L.C.; supervision and writing-review and editing, M.M. and L.A.

Funding: This research received no external funding.

Acknowledgments: The authors acknowledge Regione Lombardia and ARPA for providing their support in data collection. The authors would like to greatly acknowledge the Assistant Editor, Ms. Vanessa Sun, for her fruitfully and trustfully support during the revision process. The authors would also like to acknowledge the two anonymous reviewers for the constructive comments that helped to improve the manuscript readability and clearness.

Conflicts of Interest: The authors declare no conflict of interest.

\section{References}

1. European Community. Directive 2006/118/EC of the European Parliament and of the Council of 12 December 2006 on the Protection of Groundwater Against Pollution and Deterioration. Off. J. Eur. Union 2006, 19, 19-31.

2. EEA-European Environment Agency. European Waters-Current Status and Future Challenges: Synthesis; Publications Office of the European Union: Luxembourg, 2012. [CrossRef]

3. Lerner, D.N. Estimating Urban Loads of Nitrogen to Groundwater. Water Environ. J. 2003, 17, $239-244$. [CrossRef]

4. European Parliament. Directive (EU) 2016/2341 of the European Parliament and of the Council of 14 December 2016 on the Activities and Supervision of Institutions for Occupational Retirement Provision (IORPs). Off. J. Eur. Union 2016, 354/37, 37-85.

5. Petersen-Perlman, J.D.; Megdal, S.B.; Gerlak, A.K.; Wireman, M.; Zuniga-Teran, A.A.; Varady, R.G. Critical Issues Affecting Groundwater Quality Governance and Management in the United States. Water 2018, 10, 735. [CrossRef]

6. Kuroda, K.; Fukushi, T. Groundwater Contamination in Urban Areas. In Groundwater Management in Asian Cities: Technology and Policy for Sustainability; Takizawa, S., Ed.; cSUR-UT Series: Library for Sustainable Urban Regeneration; Springer: Tokyo, Japan, 2008; pp. 125-149, ISBN 978-4-431-78399-2. [CrossRef]

7. Masetti, M.; Poli, S.; Sterlacchini, S. The Use of the Weights-of-Evidence Modeling Technique to Estimate the Vulnerability of Groundwater to Nitrate Contamination. Nat. Resour. Res. 2007, 16, 109-119. [CrossRef] 
8. Nolan, B.T.; Hitt, K.J.; Ruddy, B.C. Probability of Nitrate Contamination of Recently Recharged Groundwaters in the Conterminous United States. Environ. Sci. Technol. 2002, 36, 2138-2145. [CrossRef] [PubMed]

9. Regione Lombardia. Deliberazione Della Giunta Regionale n. IX/3510 del 23/05/2012. Realizzazione Degli Interventi di Bonifica ai sensi dell'art. 250 del D.Lgs. 152 del 3 Aprile 2006. Programmazione Economico-Finanziaria 2012/2014. Available online: www.regione.lombardia.it/amministrazione_aperta/ 45740358 (accessed on 5 June 2019).

10. Somaratne, N.; Zulfic, H.; Ashman, G.; Vial, H.; Swaffer, B.; Frizenschaf, J. Groundwater Risk Assessment Model (GRAM): Groundwater Risk Assessment Model for Wellfield Protection. Water 2013, 5, 1419-1439. [CrossRef]

11. Alberti, L.; Colombo, L.; Formentin, G. Null-space Monte Carlo particle tracking to assess groundwater PCE (Tetrachloroethene) diffuse pollution in north-eastern Milan functional urban area. Sci. Total Environ. 2018, 621, 326-339. [CrossRef]

12. Provincia di Milano. Indagini Sulla Presenza di Composti Organo-Alogenati Nelle Acque di Falda della Provincia di Milano; S.I.F. Provincia di Milano: Milano, Italy, 1992.

13. Alberti, L.; Cantone, M.; Colombo, L.; Lombi, S.; Piana, A. Numerical modeling of regional groundwater flow in the Adda-Ticino Basin: Advances and new results. IJG 2016, 41/2016. [CrossRef]

14. Bini, A. Stratigraphy, chronology and palaeogeography of Quaternary deposits of the area between the Ticino and Olona rivers (Italy-Switzerland). Geol. Insubrica 1997, 2, 21-46.

15. Cavallin, A.; Francani, V.; Mazzarella, S. Studio idrogeologico della pianura compresa fra Adda e Ticino. Costruzioni 1983, 326/327, 39.

16. Regione Lombardia; ENI Divisione AGIP. Geologia Degli Acquiferi Padani Della Regione Lombardia [Geology of the Po Valley Aquifers in Lombardy Regio.]; S.EL.CA.: Firenze, Italy, 2001.

17. ARPA Lombardia. PROGETTO PLUMES. Available online: http://www.regione.lombardia.it/wps/portal/ istituzionale/HP/DettaglioRedazionale/istituzione/direzioni-generali/direzione-generale-ambiente-eclima/piano-per-inquinamento-diffuso (accessed on 5 June 2019).

18. Francani, V.; Beretta, G.P.; Avanzini, M.; Nespoli, M. Indagine Preliminare Sull'uso Sostenibile Delle Falde Profonde in Provincia di Milano [Preliminary Survey About Sustainable use of Deeper Groundwater in the Milan Province]; Ed. C.A.P.: Milano, Italy, 1995.

19. Afifi, A.; May, S.; Clark, V.A. Computer-Aided Multivariate Analysis, 4th ed.; Chapman and Hall/CRC: Boca Raton, FL, USA, 2003.

20. Everitt, B.S.; Landau, S.; Leese, M.; Stahl, D. Cluster Analysis, 5th ed.; John Wiley \& Sons, Ltd.: Hoboken, NJ, USA, 2011; ISBN 978-0-470-97781-1. [CrossRef]

21. Vega, M.; Pardo, R.; Barrado, E.; Debán, L. Assessment of seasonal and polluting effects on the quality of river water by exploratory data analysis. Water Res. 1998, 32, 3581-3592. [CrossRef]

22. Alberti, L.; Azzellino, A.; Colombo, L.; Lombi, S. Use of cluster analysis to identify tetrachloroethylene pollution hotspots for the transport numerical model implementation in urban functional area of Milan, Italy. In Proceedings of the SGEM2016 Conference Proceedings, Albena, Bulgaria, 30 June-6 July 2016; Volume 1, pp. 723-730. [CrossRef]

23. ARPA Lombardia. PROGETTO PLUMES - Integrazione. Available online: http://www.regione.lombardia. it/wps/portal/istituzionale/HP/DettaglioRedazionale/istituzione/direzioni-generali/direzione-generaleambiente-e-clima/piano-per-inquinamento-diffuso (accessed on 5 June 2019).

24. Colombo, L. Statistical methods and transport modeling to assess PCE hotspots and diffuse pollution in groundwater (Milan FUA). Acque Sotter. Ital. J. Groundw. 2017, 6, 15-24. [CrossRef]

25. Azzellino, A.; Colombo, L.; Lombi, S.; Marchesi, V.; Piana, A.; Andrea, M.; Alberti, L. Groundwater diffuse pollution in functional urban areas: The need to define anthropogenic diffuse pollution background levels. Sci. Total Environ. 2019, 656, 1207-1222. [CrossRef]

26. Bonham-Carter, G.F. Geographic Information Systems for Geoscientists: Modelling with GIS; Pergamon Press: New York, NY, USA, 1994.

27. Raines, G.L.; Bonham-Carter, G.F.; Kamp, L. Predictive probabilistic modeling using ArcView GIS. ArcUser 2000, 3, 45-48.

28. Agterberg, F.P.; Bonham-Carter, G.F.; Cheng, Q.; Wright, D.F. Weights of evidence modeling and weighted logistic regression for mineral potential. In Computers in Geology-25 Years of Progress; Davis, J.C., Herzfeld, U.C., Eds.; Oxford University Press: New York, NY, USA, 1993; pp. 13-23. 
29. Raines, G.L. Evaluation of Weights of Evidence to Predict Epithermal-Gold Deposits in the Great Basin of the Western United States. Nat. Resour. Res. 1999, 8, 257-276. [CrossRef]

30. Poli, S.; Sterlacchini, S. Landslide Representation Strategies in Susceptibility Studies using Weights-of-Evidence Modeling Technique. Nat. Resour. Res. 2007, 16, 121-134. [CrossRef]

31. Goetz, J.N.; Brenning, A.; Petschko, H.; Leopold, P. Evaluating machine learning and statistical prediction techniques for landslide susceptibility modeling. Comput. Geosci. 2015, 81, 1-11. [CrossRef]

32. Lee, S.; Kim, Y.-S.; Oh, H.-J. Application of a weights-of-evidence method and GIS to regional groundwater productivity potential mapping. J. Environ. Manag. 2012, 96, 91-105. [CrossRef]

33. Madani, A.; Niyazi, B. Groundwater potential mapping using remote sensing techniques and weights of evidence GIS model: A case study from Wadi Yalamlam basin, Makkah Province, Western Saudi Arabia. Environ. Earth Sci 2015, 74, 5129-5142. [CrossRef]

34. Arthur, J.D.; Wood, H.A.R.; Baker, A.E.; Cichon, J.R.; Raines, G.L. Development and Implementation of a Bayesian-based Aquifer Vulnerability Assessment in Florida. Nat. Resour. Res. 2007, 16, 93-107. [CrossRef]

35. Uhan, J.; Vižintin, G.; Pezdič, J. Groundwater nitrate vulnerability assessment in alluvial aquifer using process-based models and weights-of-evidence method: Lower Savinja Valley case study (Slovenia). Environ. Earth Sci. 2011, 64, 97-105. [CrossRef]

36. Stevenazzi, S.; Masetti, M.; Beretta, G.P. Groundwater vulnerability assessment: From overlay methods to statistical methods in the Lombardy Plain area. Acque Sotter. Ital. J. Groundw. 2017, 6, 17-27. [CrossRef]

37. Caniani, D.; Lioi, D.S.; Mancini, I.M.; Masi, S. Hierarchical Classification of Groundwater Pollution Risk of Contaminated Sites Using Fuzzy Logic: A Case Study in the Basilicata Region (Italy). Water 2015, 7, 2013-2036. [CrossRef]

38. Sawatzky, D.L.; Raines, G.L.; Bonham-Carter, G.F.; Looney, C.G. Spatial Data Modeller (SDM): ArcMAP 9.3 Geoprocessing Tools for Spatial Data Modelling Using Weights of Evidence, Logistic Regression, Fuzzy Logic and Neural Networks. 2009. Available online: http://www.ige.unicamp.br/sdm/ (accessed on 5 June 2019).

39. Masetti, M.; Sterlacchini, S.; Ballabio, C.; Sorichetta, A.; Poli, S. Influence of threshold value in the use of statistical methods for groundwater vulnerability assessment. Sci. Total Environ. 2009, 407, 3836-3846. [CrossRef] [PubMed]

40. Sorichetta, A.; Masetti, M.; Ballabio, C.; Sterlacchini, S. Aquifer nitrate vulnerability assessment using positive and negative weights of evidence methods, Milan, Italy. Comput. Geosci. 2012, 48, 199-210. [CrossRef]

41. Chung, C.-J.F.; Fabbri, A.G. Probabilistic Prediction Models for Landslide Hazard Mapping. Photogramm. Eng. Remote Sens. 1999, 65, 1389-1399.

42. Sorichetta, A.; Masetti, M.; Ballabio, C.; Sterlacchini, S.; Beretta, G.P. Reliability of groundwater vulnerability maps obtained through statistical methods. J. Environ. Manag. 2011, 92, 1215-1224. [CrossRef]

43. Stevenazzi, S.; Masetti, M.; Nghiem, S.V.; Sorichetta, A. Groundwater vulnerability maps derived from a time-dependent method using satellite scatterometer data. Hydrogeol. J. 2015, 23, 631-647. [CrossRef]

44. Goovaerts, P. Geostatistics for Natural Resources Evaluation (Applied Geostatistics); Oxford Univ. Press: New York, NY, USA, 1997.

45. Anderson, M.P.; Woessner, W.W. Applied Groundwater Modeling: Simulation to Flow and Advective Transport, 1st ed.; Academic Press: San Diego, CA, USA, 1992.

46. DUSAF-Destinazione d'Uso dei Suoli Agricoli e Forestali [Land use database]. ERSAF-Ente Regionale per i Servizi all'Agricoltura e alle Foreste. Available online: http://www.cartografia.regione.lombardia.it/ (accessed on 1 April 2019).

47. Tonkin, M.; Doherty, J. Calibration-constrained Monte Carlo analysis of highly parameterized models using subspace techniques. Water Resour. Res. 2009, 45. [CrossRef]

(C) 2019 by the authors. Licensee MDPI, Basel, Switzerland. This article is an open access article distributed under the terms and conditions of the Creative Commons Attribution (CC BY) license (http://creativecommons.org/licenses/by/4.0/). 